University of Nebraska - Lincoln

DigitalCommons@University of Nebraska - Lincoln

Faculty Publications - Chemistry Department Published Research-Department of Chemistry

June 1992

\title{
Three-Dimensional Solution Structure of Human Interleukin-4 by Multidimensional Heteronuclear Magnetic Resonance Spectroscopy
}

\author{
Robert Powers \\ University of Nebraska - Lincoln, rpowers3@unl.edu \\ Daniel S. Garrett \\ National Institute of Diabetes and Digestive and Kidney Diseases \\ Carl J. March \\ Immunex Corporation, Seattle, WA \\ Eric A. Frieden \\ Immunex Corporation, Seattle, WA \\ Angela M. Gronenborn \\ National Institute of Diabetes and Digestive and Kidney Diseases \\ See next page for additional authors
}

Follow this and additional works at: https://digitalcommons.unl.edu/chemfacpub

Part of the Chemistry Commons

Powers, Robert; Garrett, Daniel S.; March, Carl J.; Frieden, Eric A.; Gronenborn, Angela M.; and Clore, G. Marius, "Three-Dimensional Solution Structure of Human Interleukin-4 by Multidimensional Heteronuclear Magnetic Resonance Spectroscopy" (1992). Faculty Publications -- Chemistry Department. 4.

https://digitalcommons.unl.edu/chemfacpub/4

This Article is brought to you for free and open access by the Published Research - Department of Chemistry at DigitalCommons@University of Nebraska - Lincoln. It has been accepted for inclusion in Faculty Publications -Chemistry Department by an authorized administrator of DigitalCommons@University of Nebraska - Lincoln. 


\section{Authors}

Robert Powers, Daniel S. Garrett, Carl J. March, Eric A. Frieden, Angela M. Gronenborn, and G. Marius Clore 
Published in Science, vol. 256 (19 June 1992), pp. 1673-1677. Copyright @ 1992 American Association for the Advancement of Science. Used by permission. "This is the author's version of the work. It is posted here by permission of the AAAS for personal use, not for redistribution. The definitive version was published in Science."

\title{
Three-Dimensional Solution Structure of Human Interleukin-4 by Multidimensional Heteronuclear Magnetic Resonance Spectroscopy
}

\author{
Robert Powers, Daniel S. Garrett, Carl J. March, Eric A. Frieden, \\ Angela M. Gronenborn, G. Marius Clore*
}

\begin{abstract}
The three-dimensional solution structure of recombinant human interleukin-4, a protein of 133 residues and 15.4 kilodaltons that plays a key role in the immune and inflammatory systems, has been solved by multidimensional heteronuclear magnetic resonance spectroscopy. The structure is dominated by a left-handed four-helix bundle with an unusual topology comprising two overhand connections. The linker elements between the helices are formed by either long loops, small helical turns, or short strands. The overall topology is remarkably similar to that of growth hormone and granulocyte-macrophage colony stimulating factor, despite the absence of any sequence homology, and substantial differences in the relative lengths of the helices, the length and nature of the various connecting elements, and the pattern of disulfide bridges. These three proteins, however, bind to cell surface receptors belonging to the same hematopoietic superfamily, which suggests that interleukin-4 may interact with its receptor in an analogous manner to that observed in the crystal structure of the growth hormone-extracellular receptor complex.
\end{abstract}

$\mathrm{I}^{\mathrm{n}}$ nterleukin-4 (IL-4) is one of a group of cytokines that play a central role in the control and regulation of the immune and inflammatory systems (1). Specific activities associated with IL-4 are the stimulation of activated B cell, T lymphocyte, thymocyte, and mast cell proliferation and the induction of cytotoxic $\mathrm{CD}^{+} \mathrm{T}$ cells. The latter is responsible for the antitumor activity of IL4. Renal tumor cells that secrete large doses of IL-4 can establish tumor-specific immunity toward a preexisting renal cancer (2). In addition, IL-4 induces the expression of class II major histocompatibility complex (MHC) molecules and the immunoglobulin $\mathrm{E}$ ( $\mathrm{IgE}$ ) low-affinity receptor on resting B cells (3). Further, IL-4 is responsible for generating and sustaining in vivo IgE responses and for ensuring the dominance of IgG1 in the T cell-dependent immune response by causing immunoglobulin class switching of activated B cells to $\operatorname{IgE}$ and $\operatorname{IgG} 1$, respectively (3). In order to provide a structural basis for understandine the mode of action of IL-4 and its interaction with its cell surface receptor, we have determined the three-dimensional (3D) structure of human recombinant IL-4 (15.4 kD and 133 residues) in solution using multidimensional heteronuclear NMR (nuclear magnetic resonance) spectroscopy. 
The NMR structure determination was principally based on 823 approximate interproton distance restraints derived from $3 \mathrm{D}{ }^{15} \mathrm{~N}-(4)$ and ${ }^{13} \mathrm{C}$-separated (5) NOESY (nuclear Overhauser enhancement spectroscopy) spectra and a ${ }^{1} \mathrm{H}-{ }^{15} \mathrm{~N}$ HMQC (heteronuclear multiple quantum coherence)-NOESY-HMQC spectrum (6) recorded on uniformly $(>95 \%)$ labeled ${ }^{15} \mathrm{~N}$ and ${ }^{13} \mathrm{C}-{ }^{15} \mathrm{~N}-$ labeled human recombinant IL-4 $(7,8)$. These spectra were interpreted on the basis of complete ${ }^{1} \mathrm{H},{ }^{15} \mathrm{~N}$, and ${ }^{13} \mathrm{C}$ assignments obtained previously with $3 \mathrm{D}$ double- and triple-resonance NMR spectroscopy (9). [Note that a partial set of ${ }^{1} \mathrm{H}$ and ${ }^{15} \mathrm{~N}$ assignments has also been published by Redfield et al. (10)]. An example of the quality of the $3 \mathrm{D}{ }^{13} \mathrm{C}$-separated NOESY spectrum is shown in Fig. 1. The interproton distance restraints were classified into three distance ranges, 1.8 to $2.7 \AA, 1.8$ to $3.3 \AA$ [1.8 to $3.5 \AA$ for nuclear Overhauser effects (NOEs) involving NH protons], and 1.8 to $5.0 \AA$, corresponding to strong, medium, and weak NOEs, respectively $(11,12)$. With the exception of sequential $\mathrm{C} \beta \mathrm{H}(i)-\mathrm{NH}(i+1)$ NOEs, all NOEs involving side chains were derived from the $3 \mathrm{D}{ }^{13} \mathrm{C}$-separated NOESY spectrum. Although the ${ }^{1} \mathrm{H}$ chemical shift dispersion of IL-4 is small (10), the increased resolution afforded by separating the NOEs into a third dimension according to the ${ }^{13} \mathrm{C}$ chemical shift of the carbon atom attached to the destination proton is sufficient to extract a large number of NOEs unambiguously by making use of the symme-

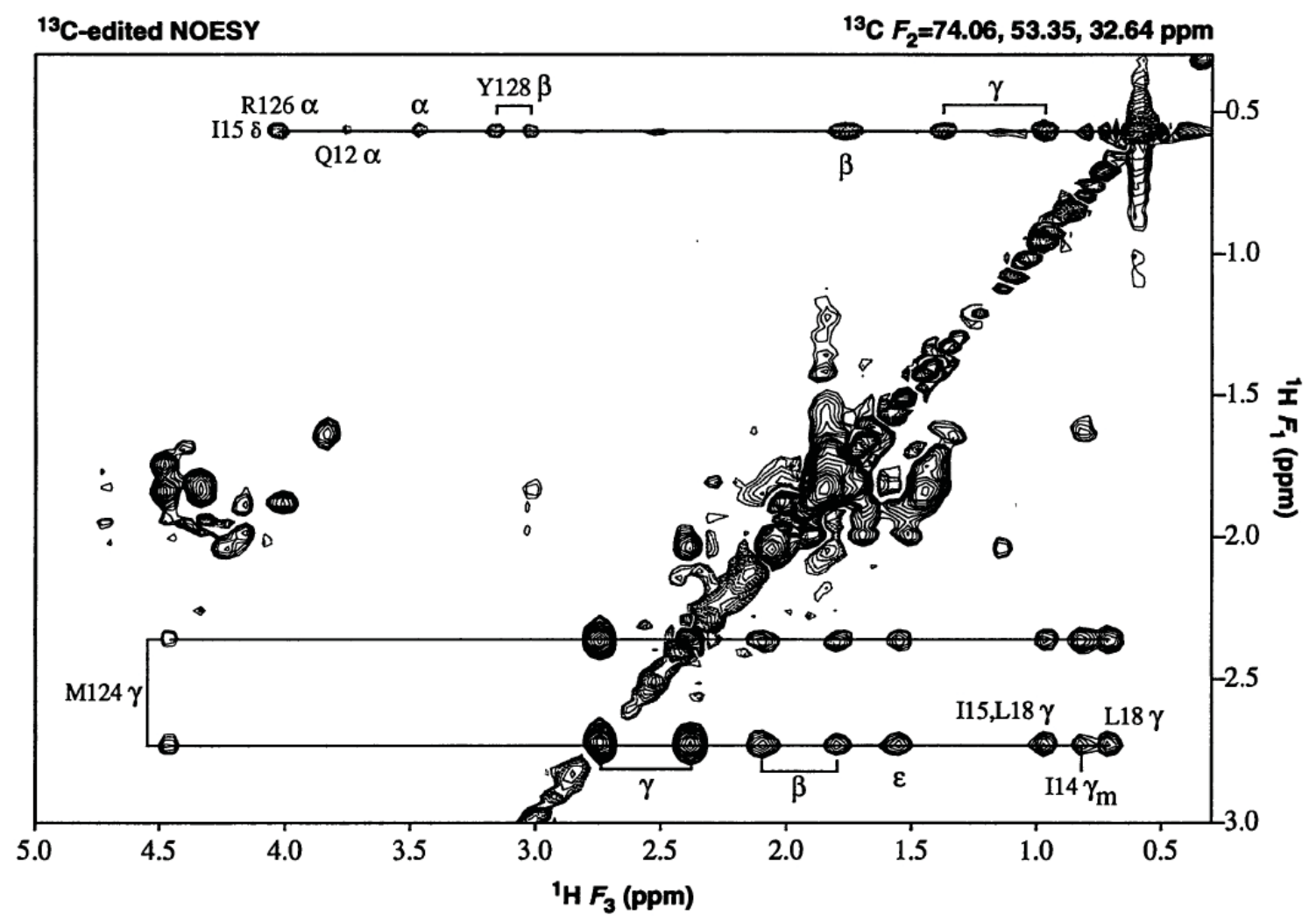

Fig. 1. Example of a ${ }^{1} \mathrm{H}\left(F_{1}\right)-{ }^{1} \mathrm{H}\left(F_{3}\right)$ plane taken at ${ }^{13} \mathrm{C}\left(F_{2}\right)=53.35 \pm 20.71 n$ ppm (where $n$ is an integer) of the 100 -ms mixing time $3 \mathrm{D}{ }^{13} \mathrm{C}$-separated NOESY spectrum of uniformly $(>95 \%){ }^{15} \mathrm{~N}-{ }^{13} \mathrm{C}$ labeled recombinant human IL-4. A number of long-range NOEs to the $\mathrm{C} \delta \mathrm{H}_{3}$ methyl group of $\mathrm{Il}^{15}$ and $\mathrm{C} \gamma \mathrm{H}$ protons of $\mathrm{Met}^{124}$ are indicated. Positive and negative contours (arising as a result of the extensive folding used in the ${ }^{13} \mathrm{C}$ dimension) are indicated by solid and dashed lines, respectively. 
try relations inherent to this spectrum. Thus, the NOE from proton $i$ to proton $j$ is labeled by the ${ }^{13} \mathrm{C}$ chemical shift of the carbon atom attached to proton $j$, and the symmetry-related NOE from proton $j$ to proton $i$ is labeled by the ${ }^{13} \mathrm{C}$ chemical shift of the carbon atom attached to proton $i$. In this manner, we readily assigned a large number of interresidue side chain-backbone and side chain-side chain NOE interactions that comprised 188 and 205 restraints, respectively (Fig. 2). The interproton distance restraints were supplemented by $101 \varphi$ torsion angle restraints derived from ${ }^{3} J_{\mathrm{HN \alpha}}$ coupling constants (13), $82 \psi$ torsion angle restraints within clearly defined helical regions derived from ${ }^{13} \mathrm{C} \alpha$ and ${ }^{13} \mathrm{C} \beta$ chemical shifts (14), and, subsequent to preliminary structure calculations, 98 distance restraints for 49 backbone $\mathrm{NH}-\mathrm{CO}$ hydrogen bonds derived from slowly exchanging backbone amide resonances $(15)$ and the pattern of medium-range $(1<|i-j| \leq 5)$ and interstrand backbone-backbone NOES within the helical and $\beta$-sheet regions, respectively (16). There are a total of 1104 experimental NMR restraints. At present no stereospecific assignments of $\beta$-methylene protons and methyl groups of Leu and Val have been obtained. Also, the structure calculations do not include any $\chi_{1}$ torsion angle restraints. Hence the present structure should be regarded as a good-quality second-generation structure (17).

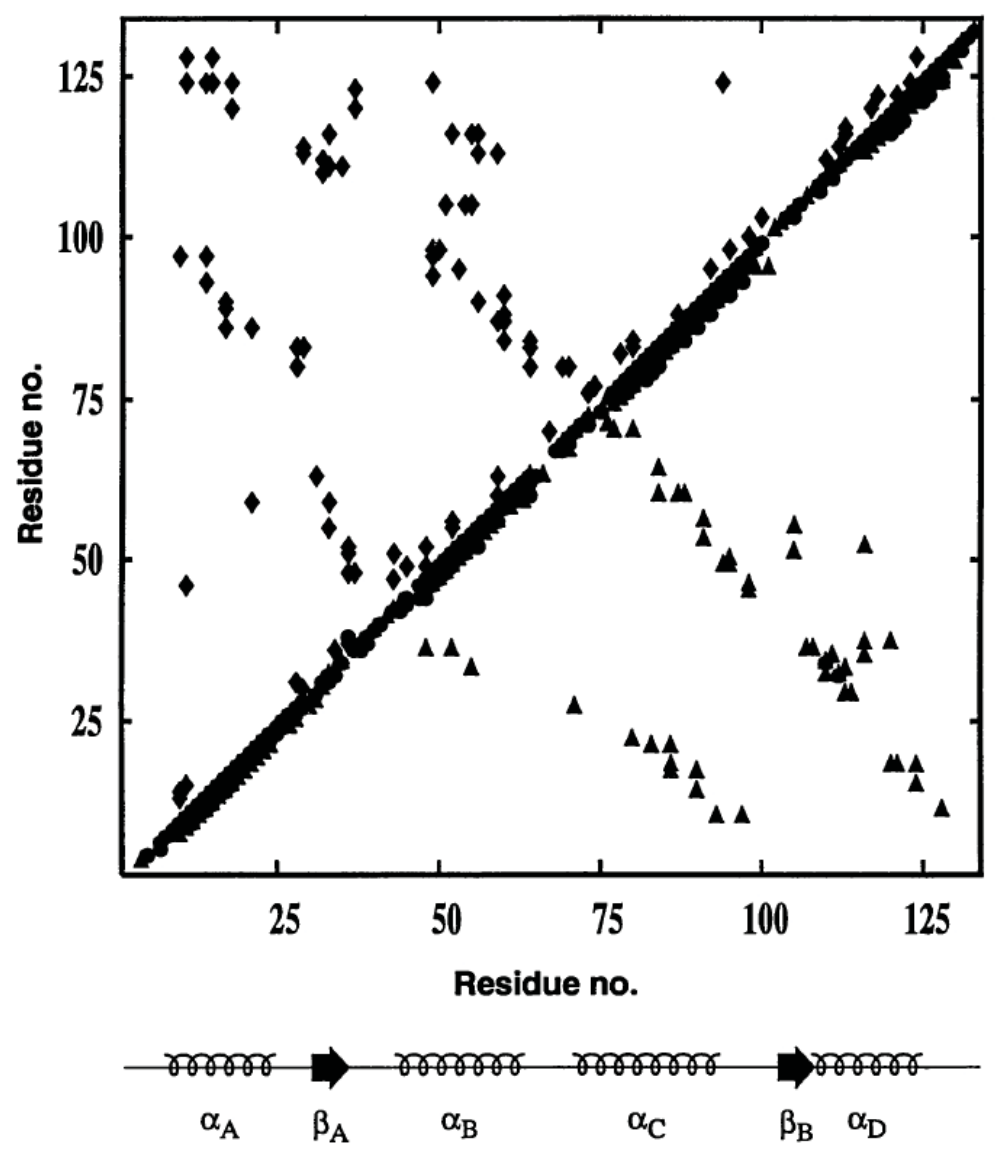

Fig. 2. Summary of the NOE connectivities assigned in the $3 D$ heteronuclear spectra of recombinant human IL-4. Side chain-side chain NOEs $(\diamond)$ are shown above the diagonal and side-chain-backbone $(\boldsymbol{\Delta})$ and backbone-backbone $(\bullet)$ NOEs are below the diagonal. The location of the four long helices comprising the four-helix bundle and the two strands is indicated below the figure. 
A total of 22 simulated annealing (SA) structures (18) were calculated with the hybrid-distance geometry-simulated annealing protocol of Nilges et al. $(19,20)$ (Table 1). All of the structures satisfy the NMR restraints within experimental error (that is, no violations greater than 0.5 $\AA$ and $5^{\circ}$ for the distance and torsion angle restraints, respectively), exhibit very small deviations from idealized covalent geometry, and display good nonbonded contacts as judged by the large negative values of the calculated Lennard-Jones van der Waals energy (21) and the solvation free energy of folding (22). A best-fit superposition of the 22 SA structures is shown in Fig. 3A. Residues 1 to 6, 132, and 133 are disordered; only residues 6 to 132 are shown in Fig. 3. The atomic root-mean-square (rms) distribution about the mean coordinate positions for residues 7 to 131 is $1.02 \pm 0.16 \AA$ for the backbone atoms and $1.50 \pm 0.17 \AA$ for all atoms; the corresponding rms values for the regions of secondary structure (residues 7 to 24,26 to 36,45 to 64, 67 to 70, 74 to 96 , and 107 to 129$)$ are $0.79 \pm 0.13$ and $1.25 \pm 0.27 \AA$, respectively (23).

Table 1. Structural statistics. The notation of the structures is as follows $\langle\mathrm{SA}\rangle$ are the $22 \mathrm{SA}$ structures; SA is the mean structure obtained by averaging the coordinates of the individual SA structures best fitted to each other (the residues used in the best fitting are 7 to 131); and $(\overline{\mathrm{SA}}) \mathrm{r}$ is the restrained minimized (regularized) mean structure obtained from SA. The number of terms for the various restraints are given in parentheses; rms, root-mean-square; and expt, experimental.

\begin{tabular}{|c|c|c|}
\hline Parameter & $\langle\mathrm{SA}\rangle$ & $(\overline{\mathrm{SA}}) \mathrm{r}$ \\
\hline \multicolumn{3}{|c|}{ Rms deviations from expt distance restraints $(\AA)^{*}$} \\
\hline All (921) & $0.033 \pm 0.005$ & 0.031 \\
\hline Sequential $(|i-j|=1)(283)$ & $0.033 \pm 0.004$ & 0.028 \\
\hline Medium range $(1<|i-j| \leq 5)(305)$ & $0.034 \pm 0.007$ & 0.029 \\
\hline Long range $(|i-j|>5)(235)$ & $0.033 \pm 0.010$ & 0.039 \\
\hline Hydrogen-bond restraints $(98) \dagger$ & $0.029 \pm 0.006$ & 0.023 \\
\hline \multicolumn{3}{|l|}{ Rms deviation from expt torsion } \\
\hline Angle restraints (degrees) $(183) \ddagger$ & $0.293 \pm 0088$ & 0.288 \\
\hline \multicolumn{3}{|l|}{ Deviations from idealized covalent geometry $\S$} \\
\hline Bonds $(\AA)(2175)$ & $0.002 \pm 0.0003$ & 0.002 \\
\hline Angles (degrees) (3929) & $0.362 \pm 0.040$ & 0.327 \\
\hline Impropers (degrees) (835) & $0.346 \pm 0.053$ & 0.297 \\
\hline$E_{\mathrm{L}-J}\left(\mathrm{kcal} \mathrm{mol}^{-1}\right) \|$ & -410 & -396 \\
\hline$S F E\left(\mathrm{kcal} / \mathrm{mol}^{-1}\right) \|$ & -139 & -149 \\
\hline
\end{tabular}

* None of the structures exhibit distance violations greater than $0.5 \AA$ or dihedral-angle violations greater than $5^{\circ}$. No intraresidue interproton distance restraints were used in the calculations The medium-range NOEs comprise 140 backbone-backbone; 113 side chain-backbone, and 52 side chain-side chain NOEs, and the long-range NOES comprise 7 backbone-backbone, 75 side chain-backbone. and 153 side chain-sidechain NOEs.

† Each hydrogen bond is characterized by two distance restraints: $r_{\mathrm{NH}-\mathrm{O}} \leq 2.3 \AA$ and $r_{\mathrm{NH}-\mathrm{O}}=2.5$ to $3.3 \AA$. All hydrogen-bonding restraints include slowly exchanging backbone amide protons.

$\ddagger$ There are $101 \Phi$ and $82 \Psi$ backbone torsion angle restraints $(13,14)$.

$\S$ The Improper torsion restraints serve to maintain planarity and chirality.

$\| E_{L-J}$ is the Lennard-Jones van der Waals energy calculated with the CHARMM (21) empirical energy function and is not included in the target function for simulated annealing or restrained minimization

II SFE is the calculated solvation free energy of folding (22) and is not included in the target function for simulated annealing or minimization. The expected value of the SFE for a protein the size of human recombinant IL-4 (133 residues) is $-135 \mathrm{kcal} \mathrm{mol}^{-1}(22)$. 

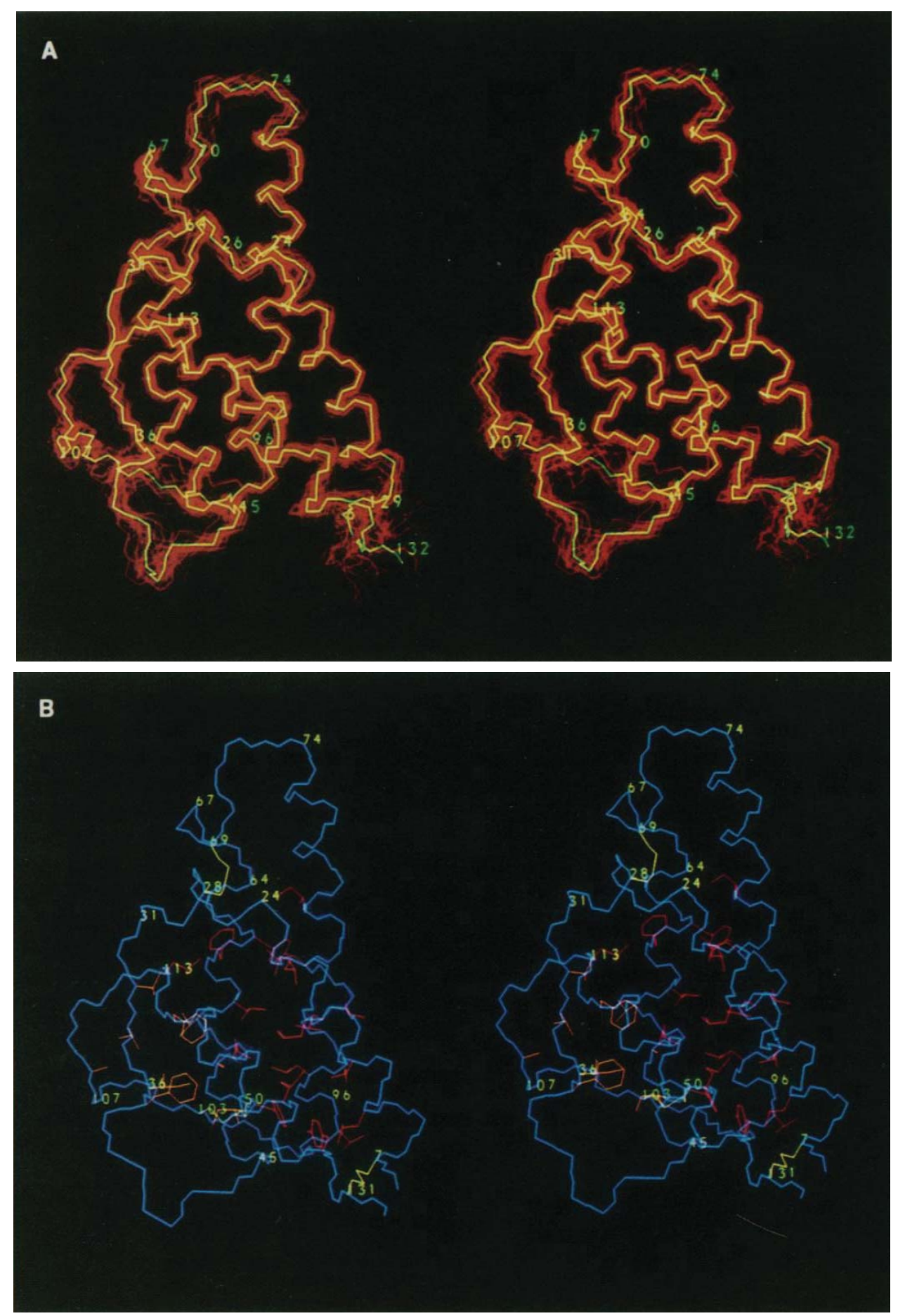

Fig. 3. (A) Stereoview of the best-fit superposition of the backbone (N, Ca, and C) atoms of the 22 SA structures (red) of recombinant human IL-4. Only residues 6 to 132 are shown as the amino and carboxyl termini are disordered, and the native sequence starts at residue 5 . The restrained minimized mean $(\overline{\mathrm{SA}}) \mathrm{r}$ structure is shown in yellow to guide the eye. (B) Stereoview of the restrained minimized mean $(\overline{\mathrm{SA}}) \mathrm{r}$ structure illustrating the hydrophobic packing within the core of the protein. The backbone is shown in blue, the three disulfide bridges (Cys $s^{7}-C_{s} s^{131}$, Cys $^{28}-$ Cys $^{69}$, and Cys ${ }^{50}-$ Cys $^{103}$ ) in yellow, the hydrophobic residues within the core of the four-helix bundle in red, and the residues involved in hydrophobic interactions between the two strands and helices $\alpha_{B}$ and $\alpha_{D}$, in orange. 
The IL-4 molecule is oblong in shape with approximate dimensions of $41 \AA$ by $28 \AA$ by $19 \AA$. The major topological feature is a left-handed four-helix bundle with an unusual connectivity in which helices adjacent to each other on a square lattice are antiparallel, whereas nonadjacent opposing helices are parallel. Thus the bundle has two overhand connections (Fig. 4). The angles and axial separations between the long axes of the four antiparallel helical pairs, $\alpha_{A}-\alpha_{C}, \alpha_{C}-\alpha_{B}$, $\alpha_{B}-\alpha_{B}$ and $\alpha_{D}-\alpha_{A}$, are $-153^{\circ}$ and $9.0 \AA,-148^{\circ}$ and $5.9 \AA,-142^{\circ}$ and $10.3 \AA$, and $-154^{\circ}$ and $9.1 \AA$, respectively. The corresponding values between the two parallel helical pairs, $\alpha_{A}-\alpha_{B}$, and $\alpha_{C}-\alpha_{D}$, are $42^{\circ}$ and $11.9 \AA$, and $45^{\circ}$ and $13.8 \AA$, respectively. The four helices have approximately similar lengths and comprise residues 7 to $24\left(\alpha_{A}\right), 45$ to $64\left(\alpha_{B}\right), 74$ to $96\left(\alpha_{C}\right)$, and 113 to $129\left(\alpha_{D}\right)$. The connecting elements between the helices are formed by either long loops, small helical turns, or short strands. Specifically, helix $\alpha_{\mathrm{A}}$ leads into a five-residue helical turn $\left(\mathrm{ht}_{\mathrm{A}}\right.$, residues 26 to 30) followed by a strand ( $\beta_{\mathrm{A}}$, residues 31 to 36) that runs in an antiparallel direction to helix $\alpha_{\mathrm{A}}$ and a loop (residues 37 to 44) that leads into helix $\alpha_{B}$. Helices $\alpha_{B}$ and $\alpha_{C}$ are connected by a short loop (residues 65 to 73 ) that contains a short four-residue helical turn ( $\mathrm{ht}_{\mathrm{B}}$, residues 67 to 70 ). The

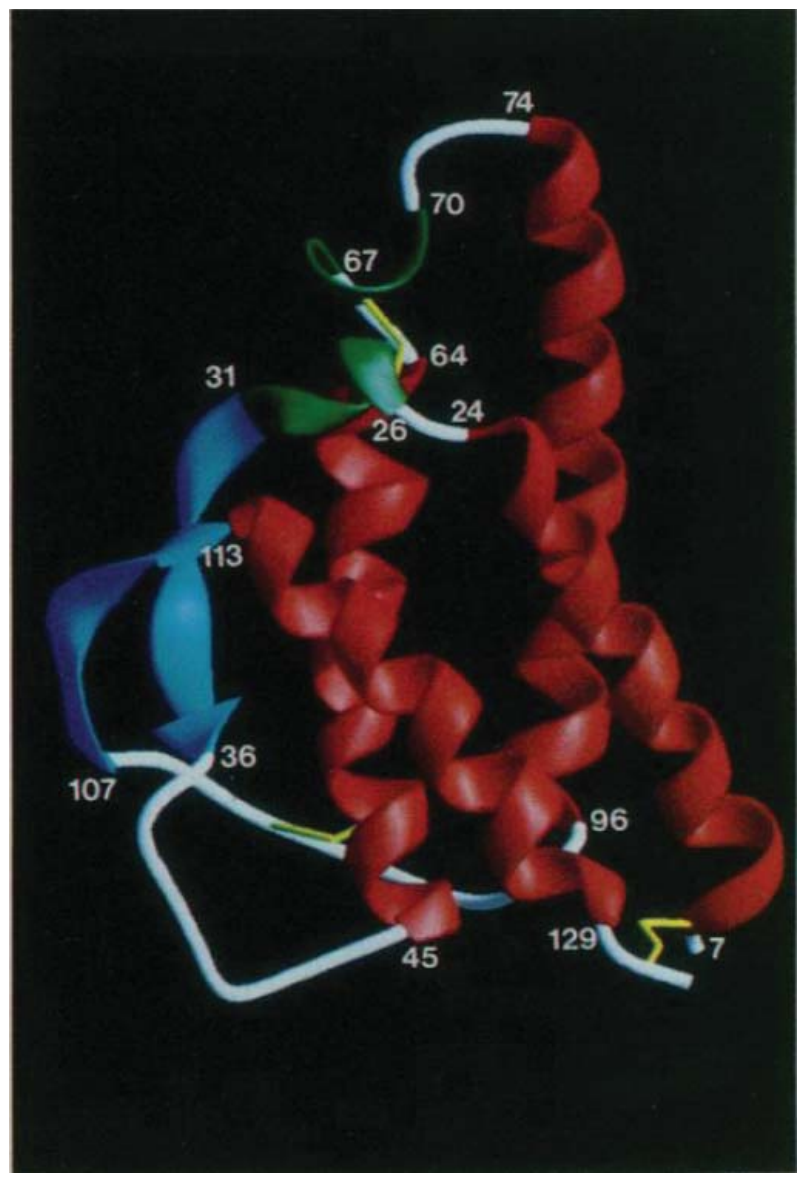

Fig. 4. Ribbon drawing of the restrained minimized mean $(\overline{\mathrm{SA}}) \mathrm{r}$ structure of recombinant human IL-4. Residues 6 to 131 are shown. The four helices $\left(\alpha_{A}, \alpha_{B}, \alpha_{C}\right.$, and $\left.\alpha_{D}\right)$ comprising the left-handed four-helix bundle are shown in red, the two small helical turns $\left(\mathrm{ht}_{\mathrm{A}}\right.$ and $\left.\mathrm{ht}_{\mathrm{B}}\right)$ in green, the two short strands $\left(\beta_{A}\right.$ and $\left.\beta_{B}\right)$ in blue, and the three disulfide bridges in yellow. The model was generated with the program Ribbon 2.0 (32). 
two helical turns, $\mathrm{ht}_{\mathrm{A}}$ and $\mathrm{ht}_{\mathrm{B}}$, are connected to each other by a disulfide bridge between $\mathrm{Cys}^{28}$ and $\mathrm{Cys}^{69}$. Helix $\alpha_{\mathrm{C}}$ leads into a loop (residues 97 to 106) and a short strand ( $\beta_{\mathrm{B}}$, residues 107 to 112) that runs antiparallel to $\alpha_{C}$ and leads directly into the fourth helix $\alpha_{D}$. The loop from residues 97 to 106 is connected to helix $\alpha_{\mathrm{B}}$ through a disulfide bridge between $\mathrm{Cys}^{103}$ and $\mathrm{Cys}^{50}$. The two strands form a mini-antiparallel $\beta$ sheet comprising residues 32 to 34 of $\beta_{\mathrm{A}}$ and 110 to 112 of $\beta_{\mathrm{B}}$. Finally, the amino terminus of helix $\alpha_{\mathrm{A}}$ and the carboxyl-terminal end of IL-4 are connected by the disulfide bridge between $\mathrm{Cys}^{7}$ and $\mathrm{Cys}^{131}$.

The internal core of the four-helix bundle is entirely hydrophobic in nature and consists of $\mathrm{Leu}^{11}$, $\mathrm{Ile}^{14}, \mathrm{Leu}^{18}$, and $\mathrm{Leu}^{21}$ of $\alpha_{\mathrm{A}}, \mathrm{Phe}^{49}, \mathrm{Ala}^{52}, \mathrm{Led}^{56}, \mathrm{Phe}^{59}$, and Tyr ${ }^{60}$ of $\alpha_{\mathrm{B}}, \mathrm{Ile}^{84}, \mathrm{Leu}^{87}$, Leu ${ }^{90}$, $\mathrm{Leu}^{94}$, and $\mathrm{Leu}^{97}$ of $\alpha_{\mathrm{C}}$, and Leu ${ }^{113}$, Leu ${ }^{117}$, Leu ${ }^{120}$, Met ${ }^{124}$, and Tyr ${ }^{128}$ of $\alpha_{\mathrm{D}}$. The packing within the hydrophobic core is shown in Fig. 3B. In addition, there are also a number of hydrophobic interactions between $\beta_{\mathrm{A}}\left(\mathrm{Thr}^{34}\right.$ and $\left.\mathrm{Ile}^{34}\right)$ and $\alpha_{\mathrm{B}}\left(\mathrm{Val}^{55}\right.$ and $\left.\mathrm{Ala}^{52}\right), \beta_{\mathrm{A}}\left(\mathrm{Val}^{33}, \mathrm{Ile}^{36}\right.$, and $\left.\mathrm{Phe}^{37}\right)$ and $\alpha_{\mathrm{D}}\left(\mathrm{Leu}^{113}, \mathrm{Phe}^{116}\right.$, Leu ${ }^{120}$, and Ile $\left.{ }^{123}\right)$, and $\beta_{\mathrm{A}}\left(\mathrm{Thr}^{34}\right)$ and $\beta_{\mathrm{B}}\left(\mathrm{Ala}^{108}\right)$ (Fig. 3B). Turns ht ${ }_{\mathrm{A}}$ and ht ${ }_{\mathrm{B}}$ are in part stabilized by side chain-backbone hydrogen bonds such as the one between $\mathrm{Thr}^{29} \mathrm{O} \gamma \mathrm{H}$ and the backbone $\mathrm{CO}$ of $\mathrm{Lys}^{25}$, and the one between the side chain carboxylate of $\mathrm{Asp}^{66}$ and the backbone $\mathrm{NH}$ of $\mathrm{Cys}^{69}$, respectively. The exterior of IL-4, on the other hand, is hydrophilic and contains a large number of positively charged Lys and Arg residues.

To our knowledge, the topology of the left-handed four-helix bundle seen in IL-4 has only been observed twice previously, namely, in the cases of growth hormone $(24,25)$ and granulocyte-macrophage colony-stimulating factor (GM-CSF) (26). Although the relative orientations of the four helices comprising the bundle are similar for the three proteins, the structural details are quite distinct, both with regard to the relative lengths of the helices and the length and nature of the various connecting elements. Thus, in the case of growth hormone, helices $\alpha_{A}$ (26 residues) and $\alpha_{D}$ (30 residues) are substantially longer than helices $\alpha_{B}$ (21 residues) and $\alpha_{C}$ (23 residues), whereas in the case of IL-4 the reverse is true with $\alpha_{A}$ (18 residues) and $\alpha_{D}$ (17 residues) being shorter than $\alpha_{B}$ (20 residues) and $\alpha_{C}$ (23 residues). In GM-CSF, on the other hand, all four helices are significantly shorter and have lengths ranging from 10 residues for $\alpha_{D}$ to 16 for $\alpha_{A}$, with the other two helices comprising 14 residues each. These differences result in a distinct alteration in the surface at the top of the front face of the three proteins in the view shown in Fig. 4. In addition, the pattern as well as the number of disulfide linkages (two in growth hormone and GMCSF versus three in IL-4) is different. Finally, there is no sequence similarity between the three proteins.

Nevertheless the overall resemblance between the topologies of IL-4, GM-CSF, and growth hormone is striking given the lack of sequence, disulfide bond, and length similarity. On the other hand, the receptors for these three proteins belong to the same hematopoietic superfamily, which also includes the receptors for interleukins-2, $-3,-5,-6$, and -7 , granulocyte colony stimulating factor, erythropoietin, prolactin, leukemia inhibitory factor, and ciliary neutrophic factor (27). The interaction of IL-4 with the extracellular domain of its receptor may be similar to that observed in the crystal structure of the growth hormone-extracellular receptor complex (25), in which case IL-4 would interact with the extracellular domains of two receptor molecules and the site of interaction with one receptor would involve the surface formed by helices $\alpha_{A}$ and $\alpha_{C}$, while the other interaction site would involve the surface formed by helix $\alpha_{D}$, strand $\beta_{A}$, and the loop connecting 
$\beta_{\mathrm{A}}$ to helix $\alpha_{\mathrm{B}}$. The first site is located at the right-hand lower edge of the molecule in the view shown in Fig. 4 and is made up of $\mathrm{Lys}^{6}, \mathrm{Glu}^{13}, \mathrm{Lys}^{16}, \mathrm{Ser}^{20}, \mathrm{Gln}^{82}, \mathrm{Arg}^{85}, \mathrm{Arg}^{89}$, and Asn ${ }^{93}$. The second site is located on the left side of the molecule in the view shown in Fig. 4 and comprises $\mathrm{Asp}^{35}, \mathrm{Asp}^{42}, \mathrm{Glu}^{45}, \mathrm{Asn}^{115}, \mathrm{Arg}^{119}, \mathrm{Glu}^{126}$, and Lys ${ }^{127}$. Despite the high degree ( 44\%) of overall sequence identity between human and mouse IL-4 (28), only 5 (Glu ${ }^{13}, \mathrm{Asp}^{42}, \mathrm{Glu}^{45}, \mathrm{Arg}^{85}$, and $\mathrm{Arg}^{89}$ ) of the 15 residues proposed to interact with the receptor are conserved, and the substitutions involve either charge removal (for example, Lys $^{6} \rightarrow$ Gly, Lys ${ }^{16} \rightarrow$ Gly, Asp ${ }^{35} \rightarrow$ Asn, Arg ${ }^{119}$ $\rightarrow$ Ser, and G1 $u^{126} \rightarrow$ Met) or charge reversal $\left(\operatorname{Ser}^{20} \rightarrow\right.$ Glu, Glu ${ }^{82} \rightarrow$ Arg, and Lys ${ }^{127} \rightarrow$ Asp) In addition, sequence alignments between the human and mouse IL-4 sequences result in a gap in the mouse sequence relative to the human one either at the beginning (28) or end of helix $\alpha_{C}(29)$, and therefore probably constitutes the region with the largest conformational differences between the human and mouse protein. This difference may account for the observation that human and mouse IL-4 do not exhibit cross-species activity with regard to either receptor binding or biological function $(30,31)$.

\section{NOTES AND REFERENCES}

${ }^{*}$ R. Powers, D. S. Garrett, A. M. Gronenborn, and G. M. Clore were at the Laboratory of Clinical Physics, National Institute of Diabetes and Digestive and Kidney Diseases, National Institutes of Health, Bethesda, Maryland. C. J. March and E. A. Frieden were at Immunex Corporation, Seattle, Washington.

1. W. E. Paul and J. Ohara, Annu. Rev. Immunol. 5, 429 (1987); T. Yokota et al. Immunol. Rev. 103, 137 (1988); F. D. Finkelman et al., Annu. Rev. Immunol. 8. 303 (1990)

2. P. T. Golumbek et al., Science 254, 713 (1991).

3. R. Kühn, K. Rajewsky, W. Müller, ibid., p. 707.

4. D. Marion et al., Biochemistry 28, 6150 (1989); E. R. P Zuiderweg and S. W. Fesik, ibid., p. 2387

5. M. Ikura, L. E. Kay, R. Tschudln, A. Bax, J Magn. Reson. 86, 204 (1990); E. R. P. Zuiderweg. L. P. Mclntosh, F. W. Dahlquist, S. W. Fesik, ibid., p. 210

6. M. Ikura. A. Bax, G. M. Clore, A. M. Gronenborn, J Am. Chem. Soc. 112, 9020 (1990).

7. All of the spectra were recorded at $36^{\circ} \mathrm{C}$ on an AM600 spectrometer equipped with a triple-resonance ${ }^{1} \mathrm{H},{ }^{15} \mathrm{~N},{ }^{13} \mathrm{C}$ probe. Quadrature detection in the indirectly detected dimensions was obtained with the TPPI-States method [D. Marion, M. Ikura, R. Tschudin, A. Bax, J. Magn. Reson. 85, 393 (1989)]. The $3 \mathrm{D}{ }^{15} \mathrm{~N}$ - and ${ }^{13} \mathrm{C}$-separated NOESY spectra were recorded with mixing times of 120 and $100 \mathrm{~ms}$, respectively, whereas the 3D ${ }^{1} \mathrm{H}-{ }^{15} \mathrm{~N}$ HMQC-NOESY-HMQC spectrum was recorded with a mixing time of 150 ms. For the ${ }^{15} \mathrm{~N}$-separated NOESY spectrum, the spectral wldth and number of points acquired were 11.4 ppm and 128 complex points in ${ }^{1} \mathrm{H}\left(F_{1}\right), 30.01 \mathrm{ppm}$ and 32 complex points in ${ }^{15} \mathrm{~N}\left(F_{2}\right)$, and $13.44 \mathrm{ppm}$ and 1024 real points in ${ }^{1} \mathrm{H}\left(F_{3}\right)$ with the ${ }^{1} \mathrm{H}$ and ${ }^{15} \mathrm{~N}$ carrier frequencies placed at 4.67 and $115 \mathrm{ppm}$, respectively. For the ${ }^{13} \mathrm{C}$-separated NOESY spectrum, the spectral width and number of points acquired were $9.26 \mathrm{ppm}$ and 128 complex points in ${ }^{1} \mathrm{H}\left(F_{1}\right), 20.71 \mathrm{ppm}$ and 32 complex points in ${ }^{13} \mathrm{C}\left(F_{2}\right)$, and $10.04 \mathrm{ppm}$ and 512 real points in ${ }^{1} \mathrm{H}\left(F_{3}\right)$ with the ${ }^{1} \mathrm{H}$ and ${ }^{13} \mathrm{C}$ carrier frequencies placed at 4.3 and $63.71 \mathrm{ppm}$. respectively. Finally, for the ${ }^{1} \mathrm{H}-{ }^{15} \mathrm{~N}$ HMQC-NOESY-HMQC spectrum, the spectral width in the ${ }^{15} \mathrm{~N}\left(F_{1}\right.$ and $\left.F_{2}\right)$ dimensions was $30.01 \mathrm{ppm}$ with the carrier at $115 \mathrm{ppm}$; and in the ${ }^{1} \mathrm{H}\left(F_{3}\right)$ dimension was $13.44 \mathrm{ppm}$ with 
the carrier at $4.67 \mathrm{ppm}$, and 64 complex points were acquired in $F_{1}, 32$ complex points in $F_{2}$ and 1024 real points in $F_{3}$. All of the spectra were processed with a single zero-filling in all dimensions on a Sun Sparc Workstation with in-house routines for Fourier transformation [L. E. Kay, D. Marion, A. Bax, ibid., 84, 72 (1989)], together with the commercially available software package NMR2 (New Methods Research, Inc., Syracuse, New York). Analysis of the 3D spectra and peak picking was carrled out with the in-house programs CAPP and PIPP [D. S. Garrett, R. Powers, A. M Gronenborn. G. M. Clore, ibid., 95, 214 (1991)].

8. Recombinant human IL-4 was expressed in yeast, uniformly isotopically labeled (with either ${ }^{15} \mathrm{~N}$ or both ${ }^{15} \mathrm{~N}$ and ${ }^{13} \mathrm{C}$ ) and purified as described previously $(9,30)$. The version of IL-4 used includes the fourresidue sequence Glu-Ala-Glu-Ala at the amino-terminus of the recombinant protein which is not part of the natural human IL-4. In this report residues are numbered from the amino-terminal Glu as residue 1, so that the natural IL-4 sequence starts at residue 5 . In addition, the two potential N-linked glycosylation sltes at $A s n^{42}$ and $A s n^{109}$ have been changed to Asp by site-directed mutagenesis to prevent hyperglycosylation in the yeast host (29).

9. R. Powers et al., Biochemistry 31, 4336 (1992); B. S. Garrett et al., ibid., p. 4347.

10. C. Redfleld et al., ibid. 30, 11029 (1991).

11. G. M. Clore et al., EMBO J. 5, 2729 (1986).

12. Upper distance limits for distances involving methyl and methylene protons were corrected appropriately for center averaging [K Wüthrich, M. Billetter, W. Braun, J. Mol. Biol. 169, 949 (1983]I. In addition. $0.5 \AA$ was added to the upper limits of distances involving methyl protons to account for the higher apparent ntensity of methyl resonances [G. M. Clore, A. M. Gronenborn, M. Nilges, C. A. Ryan. Biochemistry 26, $8012(1987)]$.

13. The ${ }^{3} \mathrm{~J}_{\mathrm{HNa}}$ coupling constants were obtained from an HMQC $J$ spectrum [L. E. Kay and A. Bax. $J$ Magn. Reson. 86, 110 (1990)] as described previously [J. D. Forman-Kay, A. M. Gronenborn, L. E. Kay, P. T. Wingfield, G. M. Clore, Biochemistry 29, 1566 (1990)]. For ${ }^{3} \mathrm{~J}_{\mathrm{HNa}}<6 \mathrm{~Hz}$ and $>8 \mathrm{~Hz}, \Phi$ was restrained to $-50 \pm 40^{\circ}$ and $-125 \pm 50^{\circ}$, respectively [A. Pardi, M. Billeter, K. Wüthrich, J. Mol. Biol. 180, 741 (1984)].

14. Restraints on $\psi$ of $-50 \pm 60^{\circ}$ in the regions of regular helix, as delineated by $\mathrm{NH}(i)-\mathrm{NH}(i+\mathrm{I}), \mathrm{CaH}(i)-$ $\mathrm{NH}(i+2,3,4]$ and $\mathrm{CaH}(i)-\mathrm{C} \beta \mathrm{H}(i+3) \mathrm{NOES}$ and the presence of slowly exchanging amide protons (16), were introduced on the basis of the ${ }^{13} \mathrm{C} \alpha$ and ${ }^{13} \mathrm{C} \beta$ chemical shifts [S. Spera and A. Bax, J. Am. Chem. Soc. 113, 5490 (1991)].

15. Slowly exchanging $\mathrm{NH}$ protons were identified by recording a series ${ }^{1} \mathrm{H}-{ }^{15} \mathrm{~N}$ Overbodenhausen correlation spectra [G. Bodenhausen and D. J. Ruben, Chem. Phys. Lett. 69, 185 (1980); A. Bax. M. Ikura, L. E. Kay, D. A. Torchia, R. Tschudin, J. Magn. Reson. 86, 304 (1990)] over a period of $\sim 24$ hours starting within 5 min of dissolving an unexchanged sample of lyophilized protein in $\mathrm{D}_{2} \mathrm{O}$.

16. K. Wüthrich, NMR of Proteins and Nucleic Acids (Wiley, New York, 1986).

17. G. M. Clore and A. M. Gronenborn, Science 252, 1390 (1991).

18. The coordinates of the $22 \mathrm{SA}$ structures and of the restrained minimized mean structure, $(\overline{\mathrm{SA}}) \mathrm{r}$, together with the experimental restraints, have been deposited in the Brookhaven Protein Data Bank.

19. M. Nilges, G. M. Clore, A. M. Gronenborn, FEBS Lett. 229, 317 (1988).

20. The hybrid distance geometry-SA protocol of (19) makes use of the program XPLOR [A. T. Brünger, G. M. Clore, A. M. Gronenborn, M. Karplus, Proc. Natl. Acad. Sci. U.S.A. 83. 3810 (1986); A. T. Brünger. XPLOR Version 3 Manual (Yale University, New Haven, 1992)] incorporating a distance geometry module [J. Kusczewski, M. Nilges, A. T. Brunger, J. Biomol. NMR 2, 33 (1992)]. The protocol involves first calculating an initial set of substructures incorporating only about one third of the atoms by projection from $n$-dimensional distance space into cartesian coordinate space, followed by SA with all atoms. The target function that is minimized during SA (as well as in conventional Powell minimization) comprises only quadratic 
harmonic potential terms for covalent geometry (that is, bonds, angles, planes, and chirality), square-well quadratic potentials for the experimental distance and torsion-angle restraints (11), and a quartic van der Waals repulsion term for the nonbonded contacts (19). All peptide bonds were restrained to be trans. There were no hydrogen-bonding, electrostatic, or 6-12 Lennard-Jones empirical potential energy terms in the target function.

21. B. R. Brooks et al.. J. Comput. Chem. 4, 1987 (1983).

22. D. Eisenberg and A. D. McLachlan, Nature 319, 199 (1986); L. Chiche, L. M. Gregoret, F. E. Cohen, P. A. Kollman, Proc. Natl. Acad. Sci. U.S.A. 87, 3240 (1990).

23. In addition to deducing the approximate location of the main secondary structure elements from a qualitative analysis of the sequential and medium-range NOE data involving backbone protons, Redfield et al. (10) also presented six preliminary structures of IL-4 based on a very limited set of long-range NOE data. The precision of these structures, which had a backbone atomic rms difference of $3.2 \AA$ ( $2.7 \AA$ for the four helices), was only sufficient to suggest that the approximate topology probably comprised a lefthanded four-helix bundle. Thus, the relative orientation of the four helices in their preliminary structures was very poorly defined and the packing of the four helices could not be defined at all. The difference in quality between these preliminary structures and those presented in this report does not therefore reflect a minor quantitative improvement in precision, but rather reflects a qualitative difference similar in nature, for example, to that between a 7 and $2.5 \AA$ resolution x-ray structure.

24. S. S. Abdel-Meguid et al., Proc. Natl. Acad. Sci. U.S.A. 84, 6434 (1987).

25. A. M. de Vos. M. Ultsch, A. A. Kossiakoff, Science 255, 306 (1992).

26. K. Diedrichs, S. Jacques, T. Boone, P. A. Karplus. J. Mol. Biol. 21, 55 (1991); K. Diedrichs, T. Boone. P. A. Karplus, Science 254, 1779 (1991).

27. D. Cosman et al., Trends Biochem. Sci. 15, 265 (1990); K. I. Arai et al., Annu. Rev. Biochem. 5, 7983 (1990); J. F. Bazan, Proc. Natl. Acad. Sci. U.S.A. 87, 6934 (1990); S. Davies et al., Science 253, 59 (1991); D. P. Gearing et al., EMBO J. 10, 2839 (1991).

28. C. Carr, S. Aykent, N. M. Kimack, A. D. Levine, Biochemistry 30, 1515 (1990).

29. B. M. Curtis et al., Proteins 11, 111 (1991).

30. L. S. Park, D. Friend, K. Grabstein, D. L. Urdal, Proc. Natl. Acad. Sci. U S.A. 84, 1669 (1987); L. S. Park, D. Friend, H. M. Sassenfeld, D. L. Urdal, J. Exp Med 166, 476 (1987).

31. K. Grabstein et al., J. Exp. Med. 163, 1405 (1986); T. Yokota et al., Proc. Natl. Acad. Sci. USA. 83, 5894 (1986).

32. M. Carson, J. Mol. Graphics 5, 103 (1987).

33. Supported by the AIDS Directed Anti-Viral Program of the Office of the Director of the National Institutes of Health (G M.C. and A.M.G.).

Submitted March 1992; accepted 23 April 1992 